\title{
Quality evaluation and UV spectrophotometric assay of ten brands of amlodipine tablets marketed in Uyo, Nigeria
}

\author{
Arnold C. IGBOASOIYI*, Amarachi P. EGEOLU and Effiong M. EDET \\ Department of Pharmaceutical and Medicinal Chemistry, Faculty of Pharmacy, University of Uyo, Uyo. Nigeria.
}

Received $12^{\text {th }}$ December 2019; Accepted $28^{\text {th }}$ February 2020

\begin{abstract}
Amlodipine is a calcium channel blocker that is widely used to treat hypertension, which is a chronic health condition characterized by persistent elevated pressure of blood in the arteries. Hypertension is a predisposing factor to stroke, kidney failure, heart diseases and vision loss. The large demand for amlodipine makes it a good candidate for fakers. Consumption of substandard and/or fake amlodipine tablets will have a negative impact on the management of hypertension. This justifies continuous monitoring of amlodipine preparations in the marketplace and the provision of simple and cost-effective assay method that could be routinely utilised for their assay. Ten different brands of amlodipine tablets were qualitatively assessed for uniformity of weight, friability, hardness, disintegration and dissolution rate using standard physical methods. Quantitative assay was carried out using spectrophotometric method. The spectrophotometric measurement was done at a wavelength of $240 \mathrm{~nm}$. Seven brands met the official requirements for uniformity of weight; eight passed the friability test and the hardness tests. All the brands tested passed the disintegration test and nine brands passed the dissolution test. The spectrophotometric assay showed that all the brands passed the United States Pharmacopoeia (USP) requirement for percentage drug content. The assay method used in this study is reliable, simple and cost-effective and can be routinely used to assay amlodipine tablets.
\end{abstract}

Keywords: Amlodipine, qualitative, quantitative, assay, ultraviolet spectrophotometry

\section{INTRODUCTION}

Amlodipine is a dihydropyridine calcium channel blocker used for the management of hypertension, coronary artery disease and angina [1-3]. It acts by inhibiting the transmembrane influx of calcium ions into vascular smooth muscles and cardiac muscles [1]. This affects their contractile process and in turn results in reduced blood pressure and contraction of the heart. Amlodipine is administered enterally, once a day as it has a half-life of 30-60 hours $[4,5]$. It reaches peak plasma concentration at 6-12 hours after oral administration, has a bioavailability of 64$90 \%$ and protein binding of $93 \%$ [6,7]. It is metabolised in the liver into many inactive pyridine metabolites and excreted primarily through the kidney [7,8]. Side effects associated with its use include oedema, headache, tiredness, abdominal pain, nausea, hypotension and heart attack $[9,10]$. It should be administered with caution in the elderly, people with heart failure and those with hepatic problem. Amlodipine is a white

\footnotetext{
*Correspondence. E-mail: igboasoiyiarnold@yahoo.com Tel: +234-8033228771.

ISSN 0189-8442

(cc) BY-NC 2020 Published by Faculty of Pharmaceutical Sciences, University of Jos, Nigeria. Under Creative Commons Attribution-NonCommercial 4.0 International License. https://creativecommons.org/licenses/by-nc/4.0/
} 
crystalline powder with a molecular formula of $\mathrm{C}_{20} \mathrm{H}_{25} \mathrm{ClN}_{2} \mathrm{O}_{5}$ and molecular weight of $408.9 \mathrm{~g} / \mathrm{mol}$ [11]. It is freely soluble in methanol, chloroform, sparingly soluble in ethanol and slightly soluble in water [12]. Amlodipine is available as the racemic mixture in $5 \mathrm{mg}$ and $10 \mathrm{mg}$ and as the $\mathrm{S}$ rotatory isomer in $2.5 \mathrm{mg}$ and $5 \mathrm{mg}$, all of oral dosage forms. Only the S (-) isomer has vasodilating action [13].

Amlodipine is manufactured by various pharmaceutical companies under various brand names. With the presence of various brands in the market, there is the probability of making inappropriate decision on the suitable brand to purchase [14]. There is a need to ascertain that every drug product meets the Pharmacopoeia standards so as to ensure optimal clinical outcomes [15]. Regular monitoring of drugs in circulation is one way of improving surveillance [14]. This necessitated our study of the different brands of amlodipine marketed in Uyo metropolis, Akwa Ibom State, Nigeria.

\section{EXPERIMENTAL}

Materials. Ten different brands of amlodipine $10 \mathrm{mg}$ tablets within their shelflives were purchased from community pharmacies in Uyo and coded A to J. The reagents used were of analytical grade and used as purchased.

Extraction of pure amlodipine. Five tablets from the innovator brand $\mathrm{H}$ (Novasc) were pulverized and extracted using $100 \mathrm{~mL}$ methanol, filtered and the solvent evaporated to obtain the amlodipine powder as crystalline solids.

Weight analysis. Twenty tablets of each brand were weighed individually using electronic weighing balance (Shimadzu, Japan). The mean weight, standard deviation and percentage deviation of each brand were calculated.
Friability test. Five tablets of each brand were weighed together to obtain weight, Wo. Each brand was subjected to friability test in a Roche friabilator at 25 revolutions per minute for 4 minutes after which each batch was reweighed to obtain weight $\mathrm{W}$. The weight loss and percentage weight loss were calculated.

Hardness test. Five tablets of each brand were randomly selected and each tablet subjected to crushing force using a Mosanto hardness tester. The average pressure at which each brand crushed was calculated.

Disintegration test. Five tablets of each brand were randomly selected and put in a digital tablet disintegration test apparatus using $900 \mathrm{~mL}$ distilled water as the disintegration medium at a bath temperature of $37^{\circ} \mathrm{C}$. The time taken for each brand to disintegrate completely was recorded.

Dissolution test. The dissolution profile of each brand of amlodipine was measured according to the method described in the British Pharmacopoeia [16] using a digital tablet dissolution apparatus in $900 \mathrm{~mL}$ of 0.1 $\mathrm{N} \mathrm{HCl}$ at $37^{\circ} \mathrm{C}$.

Spectroscopic assay. $50 \mathrm{mg}$ of the extracted amlodipine powder was dissolved in $50 \mathrm{~mL}$ of $2 \mathrm{M}$ urea solution and made up to $100 \mathrm{~mL}$ using distilled water to obtain a stock solution of $500 \mu \mathrm{g} / \mathrm{mL}$ concentration of amlodipine. The stock solution was further diluted with distilled water to get a concentration of 25 $\mu \mathrm{g} / \mathrm{mL}$, which was scanned, in the UV range of 200-350 nm against reagent blank of $2 \mathrm{M}$ urea to obtain the wavelength of maximum absorption $\left(\lambda_{\max }\right)$. Aliquots of the amlodipine stock solutions corresponding to $10 \mu \mathrm{g} / \mathrm{mL}, 20$ $\mu \mathrm{g} / \mathrm{mL}, 30 \mu \mathrm{g} / \mathrm{mL}, 40 \mathrm{mg} / \mathrm{mL}$ and $50 \mu \mathrm{g} / \mathrm{mL}$ were prepared and their absorbance measured at the $\lambda_{\max }$ of $240 \mathrm{~nm}$ against the reagent blank to obtain the calibration curve of amlodipine. Twenty tablets of each brand of amlodipine were pulverised and portions equivalent to $10 \mathrm{mg}$ of drug extracted with 14 
$\mathrm{mL}$ of $2 \mathrm{M}$ urea and $5 \mathrm{~mL}$ distilled water. The filtrates were diluted with distilled water to 10 $\mu \mathrm{g} / \mathrm{mL}$ and $20 \mu \mathrm{g} / \mathrm{mL}$ and the absorbance measured at $240 \mathrm{~nm}$ against the reagent blank. These were extrapolated on the standard curve to obtain the respective extrapolated concentrations. The percentage recoveries were obtained by comparing the extrapolated concentrations with the expected concentrations.

\section{RESULTS}

Eight brands complied with the British Pharmacopoeia specification for uniformity of weight of uncoated tablets (Table 1). Eight brands passed the friability test as they had a weight loss of less than $1 \%$ (Table 2). Nine brands passed the crushing test as shown in Table 3. All the tested brands disintegrated within the prescribed time limit (Table 4).

Nine brands passed the United States Pharmacopoeia specification for dissolution rate (Figure 1). The difference factor (f1) and the similarity factor (f2) values with respect to brand $\mathrm{H}$, the innovator brand, are shown in Table 5. The wavelength of maximum absorption of amlodipine in urea was obtained at $240 \mathrm{~nm}$ (Figure 2). Figure 3 shows the calibration curve of amlodipine. The quantitative assay results of the ten brands of amlodipine are in Table 6.

Table 1: Weight uniformity analysis of different brands of amlodipine tablets

\begin{tabular}{lllllllllll}
\hline Sample & $\mathrm{A}$ & $\mathrm{B}$ & $\mathrm{C}$ & $\mathrm{D}$ & $\mathrm{E}$ & $\mathrm{F}$ & $\mathrm{G}$ & $\mathrm{H}$ & $\mathrm{I}$ & $\mathrm{J}$ \\
\hline Mean weight(mg) & 188.80 & 402.00 & 159.35 & 152.80 & 292.30 & 191.30 & 188.75 & 402.00 & 183.75 & 405.45 \\
SD (n=10) & \pm 1.50 & \pm 3.20 & \pm 2.03 & \pm 1.25 & \pm 4.33 & \pm 11.75 & \pm 4.13 & \pm 2.99 & \pm 10.39 & \pm 5.79 \\
\% Deviation & 0.79 & 0.79 & 1.28 & 0.82 & 1.48 & 6.14 & 2.19 & 0.74 & 5.66 & 1.43 \\
\hline \multicolumn{7}{c}{ Permissible percentage deviation is 5\% } & &
\end{tabular}

Table 2: Friability analysis of different brands of amlodipine tablets

\begin{tabular}{lllllllllll}
\hline Sample & $\mathrm{A}$ & $\mathrm{B}$ & $\mathrm{C}$ & $\mathrm{D}$ & $\mathrm{E}$ & $\mathrm{F}$ & $\mathrm{G}$ & $\mathrm{H}$ & $\mathrm{I}$ & $\mathrm{J}$ \\
\hline $\mathrm{W}_{0}(\mathrm{~g})$ & 1.99 & 1.23 & 2.51 & 1.92 & 1.46 & 0.89 & 2.10 & 2.09 & 0.88 & 3.02 \\
$\mathrm{~W}(\mathrm{~g})$ & 1.98 & 1.22 & 2.49 & 1.91 & 1.44 & 0.88 & 2.09 & 2.07 & 0.87 & 3.01 \\
$\mathrm{~W}_{0}-\mathrm{W}$ & 0.01 & 0.01 & 0.02 & 0.01 & 0.02 & 0.01 & 0.01 & 0.02 & 0.01 & 0.01 \\
\% Weight loss & 0.50 & 0.81 & 0.79 & 0.52 & 1.37 & 1.12 & 0.48 & 0.95 & 0.13 & 0.33 \\
\hline
\end{tabular}

Permissible percentage weight loss is $1 \%$

Table 3: Hardness analysis of different brands of amlodipine tablets

\begin{tabular}{lllllllllll}
\hline Sample & A & B & C & D & E & F & G & H & I & J \\
\hline Average crushing strength $\left(\mathrm{Kg} / \mathrm{cm}^{2}\right)$ & 5.90 & 5.80 & 9.00 & 5.40 & 2.90 & 5.90 & 4.30 & 7.80 & 4.24 & 4.00 \\
\hline
\end{tabular}

$$
\text { Permissible crushing strength is } 4-10 \mathrm{Kg} / \mathrm{cm}^{2}
$$

Table 4: Disintegration analysis of different brands of amlodipine tablets

\begin{tabular}{lllllllllll}
\hline Sample & $\mathrm{A}$ & $\mathrm{B}$ & $\mathrm{C}$ & $\mathrm{D}$ & $\mathrm{E}$ & $\mathrm{F}$ & $\mathrm{G}$ & $\mathrm{H}$ & $\mathrm{I}$ & $\mathrm{J}$ \\
\hline Mean disintegration time $(\mathrm{min})$ & 0.23 & 0.27 & 0.27 & 0.03 & 0.36 & 1.54 & 4.51 & 0.18 & 0.02 & 0.93 \\
\hline & Permissible disintegration time is & $<15$ minutes & & & &
\end{tabular}

Table 5: $\mathrm{f} 1$ and $\mathrm{f} 2$ values of the various brands of amlodipine compared with innovator brand $\mathrm{H}$

\begin{tabular}{llllllllll}
\hline Sample & A & B & C & D & E & F & G & I & J \\
\hline F1 & 21.19 & 11.81 & 18.82 & 13.55 & 23.70 & 16.97 & 13.65 & 18.45 & 9.23 \\
F2 & 36.17 & 54.87 & 49.25 & 57.56 & 35.87 & 48.36 & 51.84 & 46.22 & 63.55 \\
\hline
\end{tabular}

Table 6: Percentage recovery of amlodipine tablets

\begin{tabular}{lllllllllll}
\hline Sample & A & B & C & D & E & F & G & H & I & J \\
\hline$\%$ & 103.38 & 100.19 & 99.53 & 100.63 & 99.43 & 97.26 & 90.00 & 98.95 & 99.27 & 99.94 \\
\hline
\end{tabular}


A.C. Igboasoiyi et al. / J. Pharmacy \& Bioresources 17(1), 60-65 (2020)

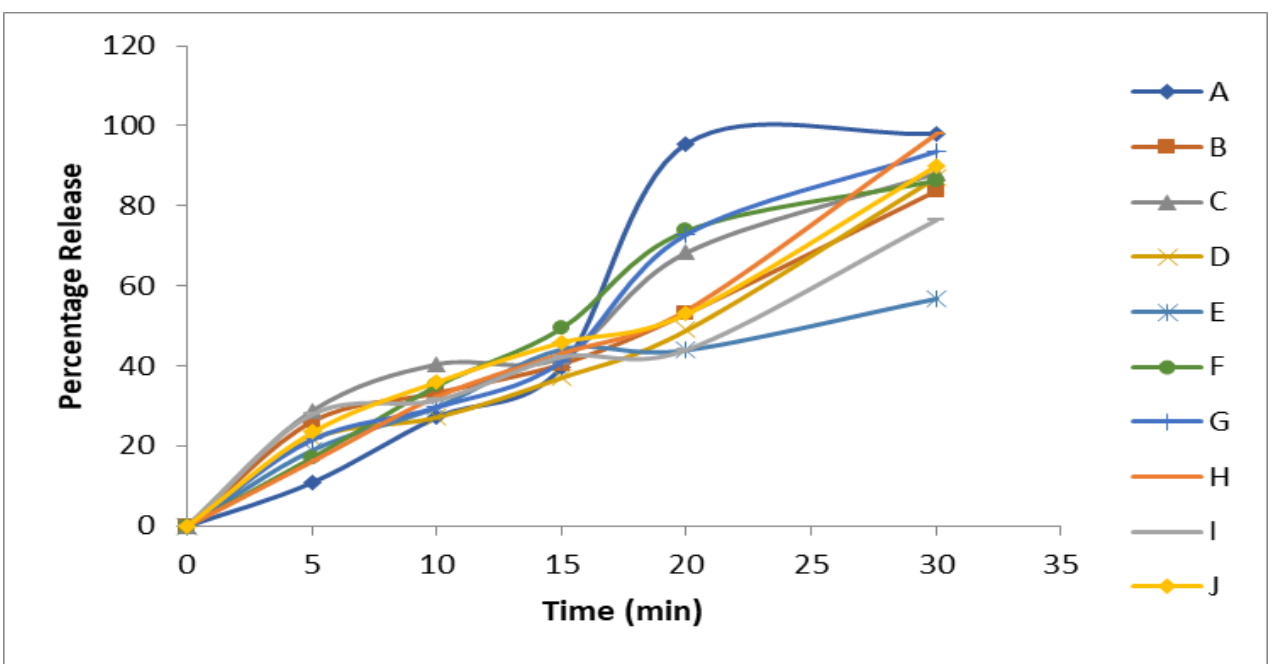

Figure 1: Dissolution analysis of different brands of amlodipine

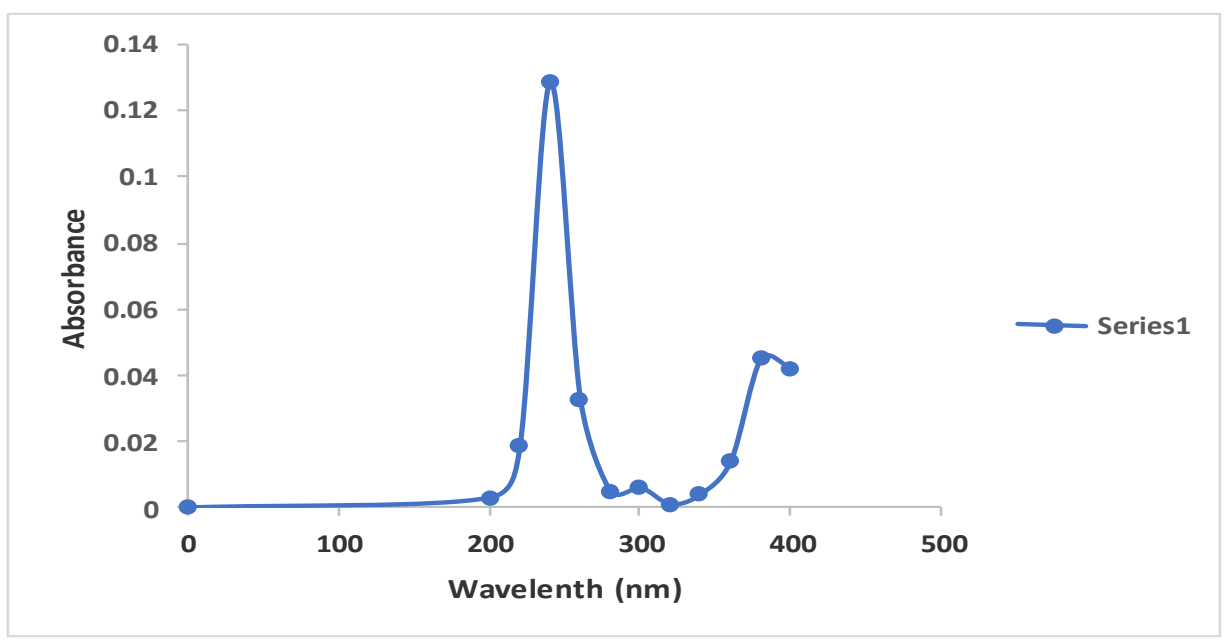

Figure 2: Absorbance spectrum of amlodipine

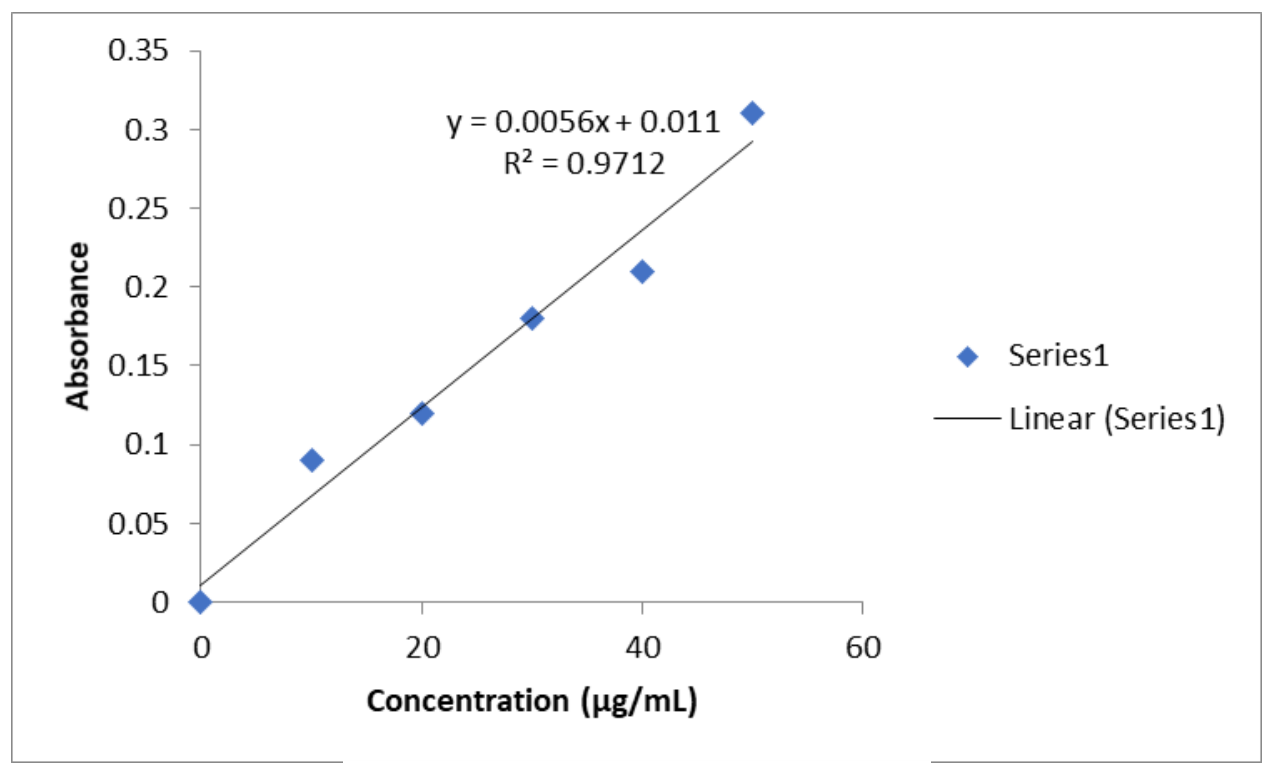

Figure 3: Calibration curve of amlodipine 


\section{DISCUSSION}

Uniformity of weight is an indication of adherence to Good Manufacturing Practice during the granulation and compression stages. British Pharmacopoeia (2015) specification for uniformity of weight of uncoated tablets is $5 \%$ deviation of each tablet from the mean value.

Friability is used to test the resistance of tablets to abrasion during packaging and transit. It is a measure of the tendency of the tablets to break into smaller pieces during contact especially by rubbing. Good friability property ensures tablets do not chip during transportation as a result of abrasion and is an evidence of adherence to good manufacturing practice. It is expected that a batch gives a weight loss of less than $1 \%$.

Crushing/hardness test measures the resistance of the tablets to chipping during handling which can influence friability and disintegration. The harder a tablet is the less friable with longer disintegration time, and vice-versa. A crushing force of between 4-0 $\mathrm{Kg} / \mathrm{cm}^{2}$ is prescribed.

Disintegration test is a quality control test used to determine the ability of solid dosage forms to break down within the prescribed period when placed in a suitable liquid medium. The rate of disintegration affects the dissolution and subsequently absorption of the drug. The presence of suitable disintegrants in adequate proportions ensures the production of tablets that are free from disintegration problems [17]. The British Pharmacopoeia (2015) specifies that uncoated tablets should disintegrate within 15 minutes.

Dissolution test is used to determine the rate of release of oral dosage forms. It is a necessary criterion for determination of drug bioavailability. It serves as a useful tool in assessing the probable in vivo performance of a drug as well as in identifying unacceptable and substandard drug products [18]. The United States Pharmacopoeia [19] specifies at least $75 \%$ dissolution in 30 minutes for amlodipine.

The difference factor (f1) and the similarity factor (f2) were calculated to compare the dissolution profiles of the various brands with the innovator product. Two dissolution profiles are considered similar and bioequivalent if $\mathrm{f} 1$ is between 0 and 15 and $\mathrm{f} 2$ is between 50 and 100 [20]. Only brands B, C, D, G, and J gave f1 values between 0 and 15 and $\mathrm{f} 2$ values between 50 and 100. These brands can be used interchangeably with brand $\mathrm{H}$ (Table 5).

The calibration curve for the extracted pure sample of amlodipine is linear over a concentration range of 10 to $50 \mu \mathrm{g} / \mathrm{mL}$ with the regression line equation obtained as $\mathrm{y}=$ $0.0056 x+0.011$ which is in conformity with Beer Lamberts Law (Figure 3). The variation of absorbance with concentration showed correlation with coefficient of correlation ( $r$ ) of 0.985 and coefficient of determination $\left(r^{2}\right)$ of value 0.971 .

From the quantitative assay results, all the ten brands met the United States Pharmacopoeia (2014) specification of $90 \%$ to $110 \%$ drug content (Table 6).

Conclusion. Only five out of nine brands assayed (55.6\%) could be used interchangeably with the innovator product, though all the brands satisfied the USP specification for drug content. Post-market surveillance is very crucial to ensure that dosage forms introduced into the market meet the required standards so as to produce effective clinical outcomes. The quantitative assay method adopted in this study can be routinely used for quick post-market surveillance of amlodipine, as it is simple, cost-effective and reproducible.

\section{REFERENCES}

1. Fares, H.; DiNicolantonio, J.J.; O’Keefe, J.H. and Lavie, C.J. (2016). Amlodipine in Hypertension: A First Line agent with efficacy for improving blood 
A.C. Igboasoiyi et al. / J. Pharmacy \& Bioresources 17(1), 60-65 (2020)

pressure and patient outcomes; Open Heart, 3(2):e000473.

2. Tiwaskar, M.; Langote, A.; Kashyap, R. and Toppo, A. (2018). Amlodipine in the era of new generation calcium channel blockers; Journal of Association of Physicians of India, 66:59-64.

3. Pavasini, R.; Camici, P. G.; Crea, F.; Danchin, N.; Fox, K.; Manolis, A. J.; Marzilli, M.; Rosano, G. M.; Lopez-Sendon, J. L.; Pinto, F. and Balla, C. (2019). Anti-angina drugs: Systematic review and clinical implications; International Journal of Cardiology, $283,55-63$.

4. Chudow, M. and Ferguson K. (2018). A case of severe refractory hypotension after amlodipine overdose; Cardiovascular toxicology, 18(2):192-197.

5. Nordmark, G.J.; Ahlner, J.; Kugelberg, F.C.; Steinwall, F.P. and Lindeman, E. (2019). A case of massive metoprolol and amlodipine overdose with blood concentrations and survival following extracorporeal corporal membrane oxygenation (ECMO); Clinical Toxicology (Phila), 57 (1), 66-68.

6. Sanghavi, K.; Someshwari, M.; Rajanandh, M.G. and Seenivasan, P. (2017. Amlodipine induced severe pedal edema: A case report from a tertiary care hospital; Journal of Pharmacovigilance, 5(243):2.

7. Johnson, R.; Dludla, P.; Mabhida, S.; Benjeddou, M.; Louw, J. and February, F. (2019). Pharmacogenomics of amlodipine and hydrochlorothiazide therapy and the quest for improved control of hypertension: a mini review; Heart Failure Reviews, 24(3):343-357.

8. Zhu, Y.; Wang, F.; Li, Q.; Zhu, M.; Du, A.; Tang, W. and Chen, W. (2014). Amlodipine metabolism in human liver microsomes and roles of CYP3A4/5 in the dihydropyridine dehydrogenation. Drug Metabolism and Disposition, 42(2):245-249.

9. Eghbali, A.; Kazemi, H.; Taherahmadi, H.; Ghandi, Y.; Rafiei, M. and Bagheri, B. (2017). A randomized, controlled study evaluating effects of amlodipine addition to chelators to reduce iron loading in patients with thalassemia major; European Journal of Haematology, 99(6):577-581.

10. Vukadinovic, D., Scholz, S.S., Messerli, F.H., Weber, M.A., Williams, B., Bohm, M. and Mahfoud, F. (2019). Peripheral edema and headache associated with amlodipine treatment: a meta-analysis of randomized, placebo-controlled trials. Journal of Hypertension, 37(10):2093-2103.
11. Kishore, C.R. and Mohan, G.K. (2016). Development and validation of amlodipine impurities in amlodipine tablets using design space computer modelling; American Journal of Analytical Chemistry, 7(12):918.

12. Uddin, A.B.M.H.; Alaamaa, M.; Zaidul, I.S.M.; Abbas, S.A.; Awang, M. and Fahim, T.K. (2017). Current analytical methods for amlodipine and its formulations: A review. Journal CleanWAS, 1(1):1722.

13. Ohmori, M.; Arakwa, M.; Harada, K.; Takasaki, H.; Hifumi, S.; Miyamori, I. and Fujimura, A. (2003). Stereoselective pharmacokinetics of amlodipine in elderly hypertensive patients; American Journal of Therapeutics, 10(1):29-31.

14. Igboasoiyi, A.C.; Offor, A.C. and Egeolu, A.P. (2018). Quality Assessment of Various Brands of Ciprofloxacin Hydrochloride Tablets Sold In Uyo Metropolis; Nigerian Journal of Pharmaceutical and Applied Science Research, 7(2):89-93.

15. Igboasoiyi, A.C.; Egeolu, A.P. and Amos, B.G. (2019). Quality Assessment of Various Brands of Lisinopril Tablets Sold in Uyo Metropolis using UV spectrophotometry; Nigerian Journal of Pharmaceutical and Applied Science Research, 8(2):38-43.

16. British Pharmacopoeia (2015). Monographs on medicinal and pharmaceutical substances. Her majesty's stationery office, London. 1:535-538.

17. Jantratid, E., Janssen, N., Reppas, C. and Dressman, J.B. (2008). Dissolution Media Simulation Conditions in the Proximal Human Gastrointestinal Tract: An Update; Pharmaceutical Resources, 25:1663-1676.

18. Shah, V.P. (2001). Dissolution: a quality control test vs a bioequivalent test; Dissolution Technologies 8(4):1-2.

19. United States Pharmacopoeia, National Formulary USP 37, NF 32. (2014). Amlodipine Official Monograph, United States Pharmacopeial Convention 12601. Twinbrook, Parkway, Rockville MD 20852, 2:1761-1762.

20. United States Food and Drug Administration, Center for Drug Evaluation and Research (1997). Guidance for industry: Dissolution testing of immediate release solid oral dosage forms; available at: http://www.fda.gov/cder/Guidance/1713bp1.pdf. 